\title{
A Comparative Study of Thyroid Cytology Reporting by Bethesda System and Routine Cytology in a Teaching Institute of Sub Himalayan Region
}

\author{
Nirmalesh Mahata $^{1}$ and Indranil Chakrabarti ${ }^{2 *}$ \\ ${ }^{1}$ Department of Pathology, Mal Superspeciality Hospital, Jalpaiguri, India \\ ${ }^{2}$ Department of Pathology, North Bengal Medical College, Darjeeling, India
}

\begin{abstract}
Introduction: Fine needle aspiration cytology (FNAC) is an important preoperative diagnostic tool for thyroid lesions which are endemic in the Sub-Himalayan belt. But sometimes, the FNAC procedures are unable to guide clinicians for definite management. Bethesda System for Reporting Thyroid Cytology (BSRTC) has been formulated to be more sensitive and specific than routine cytological examination in diagnosis of thyroid swellings and act a better tool than the latter due to its objectivity. It may, thus, improve the clinical management of thyroid diseases and even may prevent unnecessary thyroidectomy.
\end{abstract}

Aims and Objective: The study is aimed to compare the interpretation of thyroid FNAC smears by conventional reporting and by BSRTC in patients of thyroid swellings in the Sub-Himalayan regions.

Material and Methods: This observational study was done at the Department of Pathology from July 2015 to June 2016 . Total 145 cases of thyroid swellings were included for study and reported by both BSRTC and conventional (routine) reporting system. Each of the reporting system was correlated with the available histopathological findings and statistical assessments were performed.

Results: Among the total 145 cases, colloid nodules followed by thyroiditis were most common benign conditions in both the reporting systems and among the malignancies; papillary carcinoma was the most predominant. Statistical assessment showed that sensitivity, specificity as well as positive and negative predictive values was higher in BSRTC compared to the conventional reporting system.

Conclusion: BSRTC is more accurate than conventional reporting system for thyroid cytology and its management strategy can help to prevent unnecessary thyroidectomy.

Keywords: Thyroid Swelling, FNAC, Conventional Reporting System, BSRTC

\section{Introduction}

Thyroid swelling is an important worldwide problem and is more common among South Asian women. ${ }^{[1]}$ The SubHimalayan belt is an endemic zone of goitrous thyroid diseases. ${ }^{[2]}$ The area of the study is included in this belt. Fine Needle Aspiration Cytology (FNAC) was introduced for the same purpose and quickly it became widely accepted as an important diagnostic tool among clinicians due to its good patient compliance and cost effectiveness. Moreover, FNAC evaluation of thyroid swelling reduces load of unnecessary surgeries for benign lesion and opens the way to timely surgical intervention when there is significant risk of malignancy ${ }^{[3]}$ However, some diagnosis cannot be reliably made on routine FNAC procedure as for example, differentiation between follicular adenoma and minimally invasive follicular carcinoma. As a result, certain number of misdiagnosis is unavoidable. Inter-observer variability and inadequate aspiration also limit the effectiveness of this procedure. Again, various institutes have their own system of reporting of cytology smears. Hence, standardized categorical systems for FNAC reporting can make results easier to understand for clinicians and give clear indications for therapeutic action. BSRTC streamlines the assessment and reporting of thyroid aspirates and alleviates the interobserver variability of this procedure.

This system categorizes the FNAC diagnosis into six groups with well defined cancer risk and clear indications for further clinical management. ${ }^{[4]}$ A few studies conducted in Western countries reported a good diagnostic concordance between BSRTC and available histologic diagnosis; however such type of data is scarcely available in this country ${ }^{[5]}$ as well as in this part of the country.

Hence, the study is aimed to evaluate the interpretation of diagnosis for thyroid swelling by both BSRTC and routine cytology and to assess superior correlation of BSRTC, if any, with available histopathology in the study population in the northern region of West Bengal. 


\section{Materials and Methods}

It was an observational study conducted in the northern region of West Bengal for a period of one year after obtaining clearance from the Institutional ethics committee. The patients who presented with clinical or radiologically diagnosed cases of goiter were included in the study after obtaining informed written consent. Those with already diagnosed thyroid lesions or on cytotoxic drugs known to cause thyroid enlargement were excluded from the study. As per the above criteria, the total numbers of cases were 145 . The thyroid FNA smears were classified into group A (for BSRTC) and group B (for routine cytology). The diagnostic accuracy of each reporting protocol was compared in relation to the gold standard i.e. histopathology. Total numbers of available histopathology reports were 58 .

The cases were diagnosed and placed as per the conventional method of reporting, ${ }^{[6]}$ under the following categories:

A) Nondiagnostic/Unsatisfactory: Cases were categorized into this group when the aspirations were not fulfilling the adequacy criteria of thyroid cytology. The adequacy criteria for thyroid cytology ${ }^{[7-9]}$ are:

1. The sample should contain at least six group of well visualized (not obscured by blood, not a thick smear) thyroid follicular cells.

2. Each group should contain at least 10 thyroid follicular cells, preferably on a single slide.

Exceptions of these criteria were applied to the following special circumstances ${ }^{[7]}$ :

a) Solid nodules with cytologic atypia

b) Solid nodules with inflammation

c) Colloid nodules

B) Benign: When the aspirates were obtained from multinodular goiters, benign microfollicular adenoma, colloid nodules and various thyroiditis. ${ }^{[10]}$

C) Indeterminate (Suspicious for Malignancy): Conditions where there were presence of atypical cellular features but not fulfilling the definite diagnosis of malignancy. ${ }^{[1]]}$

D) Malignant: Conditions where there were presence of features suggesting definite diagnosis of following malignant conditions $^{[12]}$ e.g. Papillary Carcinoma, Medullary carcinoma, Anaplastic Carcinoma, Lymphomas and Metastatic tumors.

The same cases were also categorized according to BSRTC (Table 1).$^{[13]}$
Histopathological diagnosis of the available biopsy specimens were taken as gold standard for correlation of the cytological reporting.

\section{Results}

Distribution of all cases according to conventional method of reporting was represented as in Table 2 and distributions of cases according to BSRTC were represented as in Table 3.

For statistical assessment among the total 145 cases only 58 cases who were undergone biopsy, were included and subcategorized according to their cytological diagnostic system into "Positive for neoplasia" and "Negative for neoplasia" in relation to gold standard histopathological findings. For conventional reporting system, total 26 cases that included the "Indeterminate (Suspicious for malignancy)" and "Malignant" lesions were grouped into "Positive for neoplasia" on the other hand, remaining 32 cases those who were subcategorized into the "Inadequate" and "Benign" lesions were grouped into "Negative for neoplasia" and statistical analysis was then performed. Similarly, according to BSRTC, the categories IV to VI were grouped into "Positive for neoplasia" (total 21 cases) and remaining category I to III lesion types (total 37 cases) were grouped into "Negative for neoplasia" for statistical assessment considering biopsy as gold standard. The comparative studies of statistical parameters were shown in Table 4. In our study the sensitivity, specificity, positive predictive value (PPV), negative predictive value (NPV) and diagnostic accuracy of BSRTC were 95\%, 94.74\%, $90.47 \%, 97.29 \%$ and $94.83 \%$ respectively. Among them, specificity as well as PPV was significantly higher in BSRTC than conventional system.

\section{Discussion}

Thyroid nodules are one of the commonest clinical problems and FNAC of the thyroid is the first line preoperative investigation of thyroid lesions. The majority of nodules are benign, mostly non neoplastic. The present study was carried out with an aim to evaluate the role of FNAC in diagnosis of various neoplastic and non neoplastic lesions of thyroid and to assess the superior correlation of BSRTC compared to conventional cytology reporting. In their study, Raab et al ${ }^{\left[{ }^{14]}\right.}$ mentioned that "Unsatisfactory" specimens may be grouped into "Negative for neoplasia" as like benign categories. On the other hand, Papanicolaou Society of Cytopathology ${ }^{[15]}$ and the American Association of Clinical Endocrinologists ${ }^{[16]}$ told that "Indeterminate" cytologic category should be treated as like "Malignant" lesions for better management. According to Nadira Mamoon et al. ${ }^{[17]}$ the conventional reporting system of thyroid cytology were categorized into inadequate, benign, suspicious, and malignant where the follicular neoplasm 
Table 1: Distribution of categories according to Bethesda system.

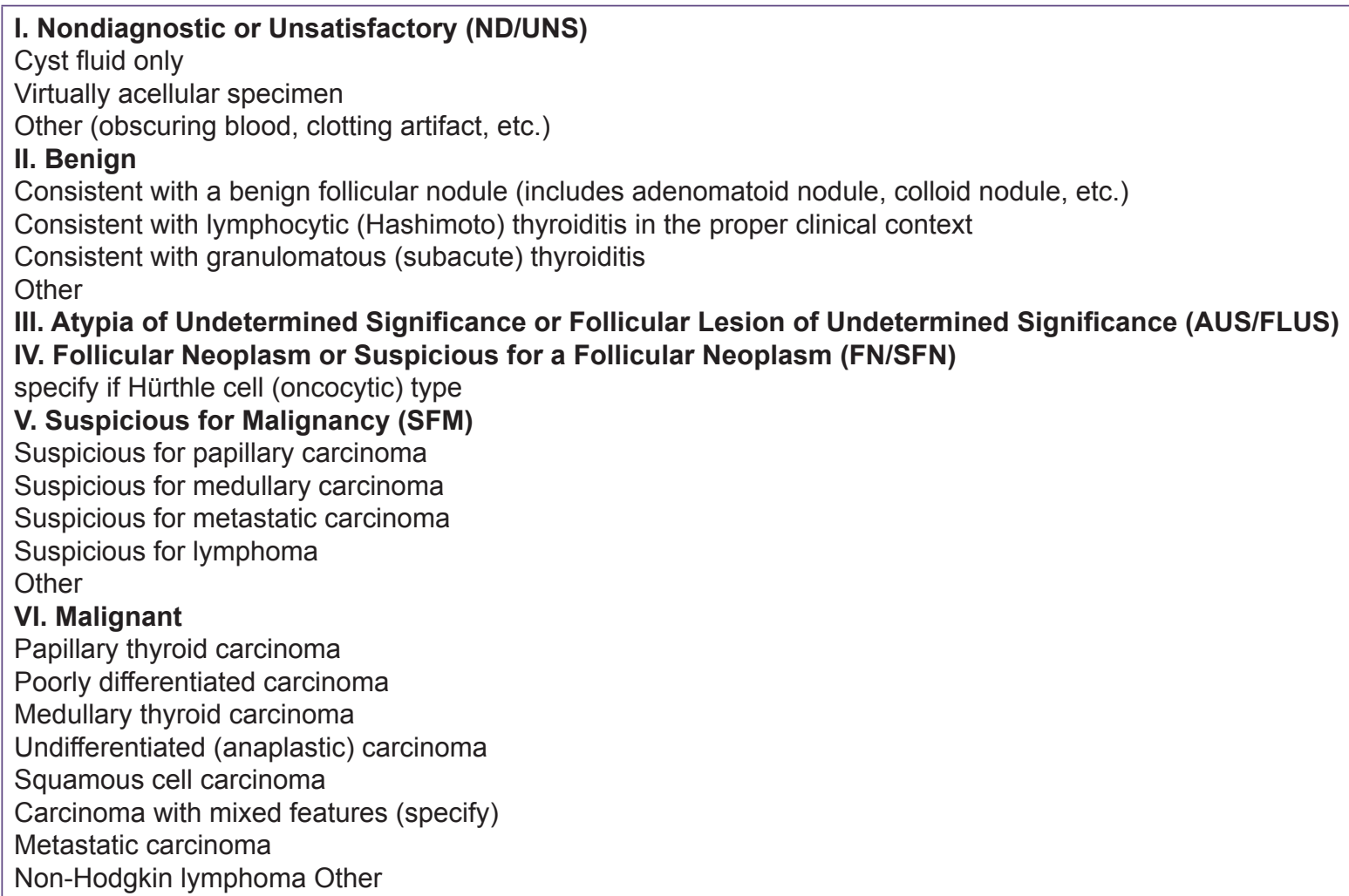

\section{Malignant}

Papillary thyroid carcinoma

Poorly differentiated carcinoma

Medullary thyroid carcinoma

Undifferentiated (anaplastic) carcinoma

Squamous cell carcinoma

Carcinoma with mixed features (specify)

Metastatic carcinoma

Non-Hodgkin lymphoma Other

Table 2: Distribution of cases according to conventional reporting system.

\begin{tabular}{|c|c|c|c|c|}
\hline \multicolumn{2}{|c|}{ Type of cases } & \multicolumn{2}{|c|}{ Number of cases } & Percentage \\
\hline \multicolumn{2}{|l|}{ Inadequate } & \multicolumn{2}{|c|}{11} & 7.59 \\
\hline \multirow{4}{*}{ Benign } & Colloid goitre \& changes & 52 & \multirow{4}{*}{ Total 105} & \multirow{4}{*}{ 72.41(Total) } \\
\hline & Nodular goiter & 7 & & \\
\hline & Adenomatoid goiter & 6 & & \\
\hline & Thyroiditis \& changes & 40 & & \\
\hline \multicolumn{2}{|c|}{ Indeterminate (suspicious to be malignant ) } & \multicolumn{2}{|c|}{16} & 11.03 \\
\hline \multirow{5}{*}{ Malignant } & Papillary carcinoma (PTC) & 7 & \multirow{5}{*}{ Total 13} & \multirow{5}{*}{8.97 (Total) } \\
\hline & Medullary carcinoma (MTC) & 2 & & \\
\hline & Anaplastic carcinoma (AC) & 2 & & \\
\hline & Metastasis & 1 & & \\
\hline & Poorly differentiated carcinoma & 1 & & \\
\hline \multicolumn{2}{|l|}{ Total } & \multicolumn{2}{|c|}{145} & 100 \\
\hline
\end{tabular}

Table 3: Distribution of cases according to Bethesda system.

\begin{tabular}{|c|c|c|c|c|}
\hline \multicolumn{2}{|l|}{ Type of cases } & \multicolumn{2}{|c|}{ Number of cases } & Percentage \\
\hline \multicolumn{2}{|c|}{ Inadequate (Category I) } & \multicolumn{2}{|c|}{11} & 7.59 \\
\hline \multirow{4}{*}{ Benign (Category II) } & Colloid goitre \& changes & 52 & \multirow{4}{*}{ Total 103} & \multirow{4}{*}{ 71.03(Total } \\
\hline & Nodular goiter & 7 & & \\
\hline & Adenomatoid goiter & 4 & & \\
\hline & Thyroiditis \& changes & 40 & & \\
\hline
\end{tabular}




\begin{tabular}{|c|c|c|c|c|}
\hline \multicolumn{2}{|l|}{ Type of cases } & \multicolumn{2}{|c|}{ Number of cases } & Percentage \\
\hline \multicolumn{2}{|c|}{ AUS/FLUS (Category III) } & \multicolumn{2}{|c|}{8} & 5.51 \\
\hline \multirow{2}{*}{$\begin{array}{l}\text { FN/ SFN } \\
\text { (Category IV) }\end{array}$} & $\begin{array}{l}\text { Suggestive of follicular } \\
\text { neoplasm }\end{array}$ & 6 & \multirow{2}{*}{ Total 7} & \multirow{2}{*}{4.83 (Total) } \\
\hline & $\begin{array}{l}\text { Suggestive of Hurthle cell } \\
\text { neoplasm }\end{array}$ & 1 & & \\
\hline \multirow{5}{*}{$\begin{array}{l}\text { SFM } \\
\text { (Category V) }\end{array}$} & $\begin{array}{l}\text { Suspicious for Papillary } \\
\text { Carcinoma }\end{array}$ & 3 & \multirow{5}{*}{ Total 7} & \multirow{5}{*}{4.83 (Total) } \\
\hline & Suspicious for lymphoma & 1 & & \\
\hline & $\begin{array}{l}\text { Suspicious for Poorly } \\
\text { differentiated carcinoma }\end{array}$ & 1 & & \\
\hline & $\begin{array}{l}\text { Suspicious for Medullary } \\
\text { Carcinoma }\end{array}$ & 1 & & \\
\hline & Metastasis & 1 & & \\
\hline \multirow{3}{*}{$\begin{array}{l}\text { Malignant } \\
\text { (CategoryVI) }\end{array}$} & Papillary carcinoma (PTC) & 6 & \multirow{3}{*}{ Total 9} & \multirow{3}{*}{6.21 (Total) } \\
\hline & \begin{tabular}{|l|} 
Medullary carcinoma (MTC) \\
\end{tabular} & 1 & & \\
\hline & Anaplastic carcinoma (AC) & 2 & & \\
\hline \multicolumn{2}{|l|}{ Total } & \multicolumn{2}{|c|}{145} & 100 \\
\hline
\end{tabular}

AUS/FLUS: Atypia of Undetermined Significance / Follicular Lesion of Undetermined Significance FN/ SFN: Follicular Neoplasm / Suspicious for a Follicular Neoplasm

SFM: Suspicious for Malignancy

Table 4: Statistical assessment of conventional reporting system and BSRTC.

\begin{tabular}{|c|c|c|c|}
\hline & & \multicolumn{2}{|c|}{ Biopsy } \\
\hline & & Neoplastic & Non-neopastic \\
\hline \multirow{3}{*}{$\begin{array}{l}\text { Conventional } \\
\text { reporting system }\end{array}$} & Positive (26) & $18(\mathrm{TP})$ & 08 (FP) \\
\hline & Negative (32) & $02(\mathrm{FN})$ & $30(\mathrm{TN})$ \\
\hline & Total $(n=58)$ & 20 (TP+FN) & 38 (FP+TN) \\
\hline \multirow{3}{*}{ BSRTC } & Positive (21) & $19(\mathrm{TP})$ & 02 (FP) \\
\hline & Negative (37) & $01^{`}(\mathrm{FN})$ & $36(\mathrm{TN})$ \\
\hline & Total $(n=58)$ & $20^{\circ}(\mathrm{TP}+\mathrm{FN})$ & 38 (FP+TN) \\
\hline
\end{tabular}

TP: True Positive, TN: True Negative, FP: False Positive, FN: False Positive

Table 5: Comparative studies.

\begin{tabular}{|c|c|c|c|c|}
\hline & Statistical analysis (\%) & $\begin{array}{l}\text { Present study } \\
\qquad(n=58)\end{array}$ & $\begin{array}{l}\text { Mamatha et al. }{ }^{[19]} 2015 \\
\qquad(n=240)\end{array}$ & $\begin{array}{c}\text { Bukhari et al. }{ }^{[20]} 2012 \\
(n=120)\end{array}$ \\
\hline \multirow{4}{*}{$\begin{array}{l}\text { Routine reporting } \\
\text { system }\end{array}$} & Sensitivity & 90 & 77 & 85 \\
\hline & Specificity & 78.95 & 69 & 65 \\
\hline & PPV & 69.23 & 37 & 32 \\
\hline & NPV & 93.75 & 93 & 95.5 \\
\hline \multirow{4}{*}{ BSRTC } & Sensitivity & 95 & 100 & 100 \\
\hline & Specificity & 94.74 & 82.5 & 82.5 \\
\hline & PPV & 90.47 & 45 & 45 \\
\hline & NPV & 97.29 & 100 & 100 \\
\hline
\end{tabular}

PPV: Positive Predictive Value, NPV: Negative Predictive Value 


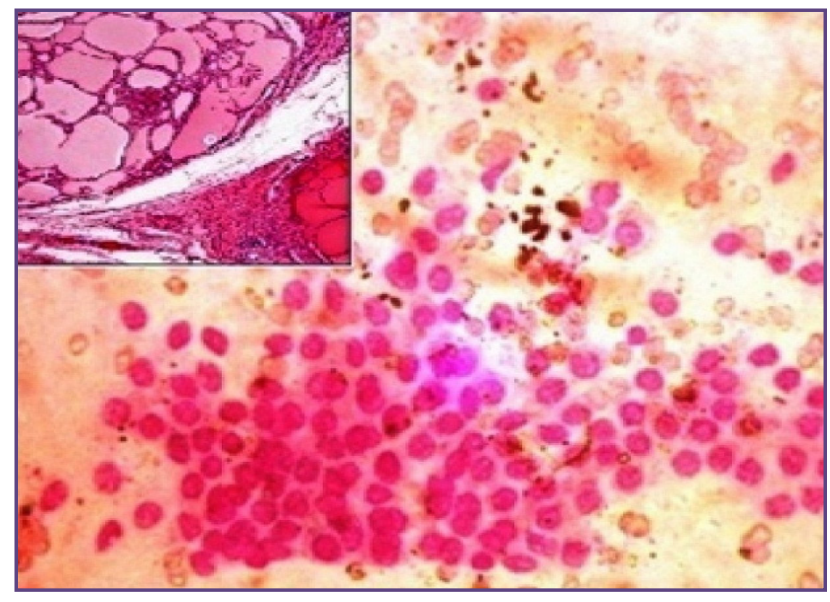

Fig. 1- FNA diagnosis- Nodular goitre (BSRTC Category II) [H/E $100 X$ ] along with Histopathology image on inset (H/E 10X).

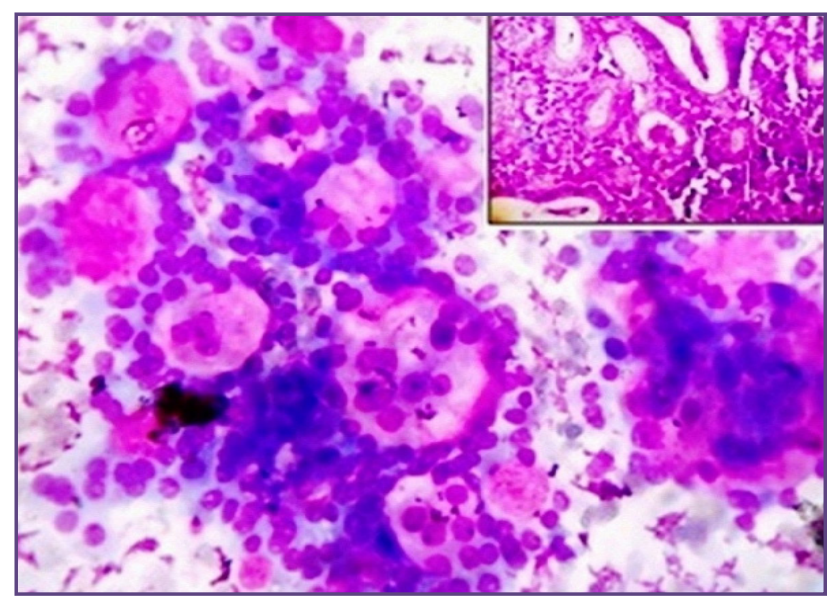

Fig. 3: FNA diagnosis- "Suspicious for follicular malignancy" in routine cytology \& Category IV in BSRTC (Leishman 400X) that was diagnosed as Follicular carcinoma on biopsy (H/E 400X) [Inset].

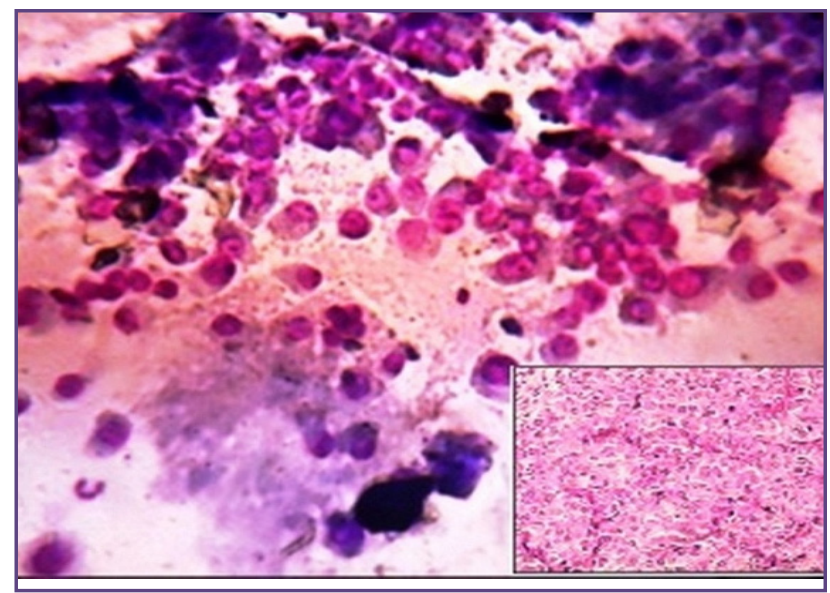

Fig. 5: FNA diagnosis- Suspicious for Medullary carcinoma in BSRTC (Category V) [Leishman stain 400X] which was confirmed on biopsy [H/E 400X] [Inset].

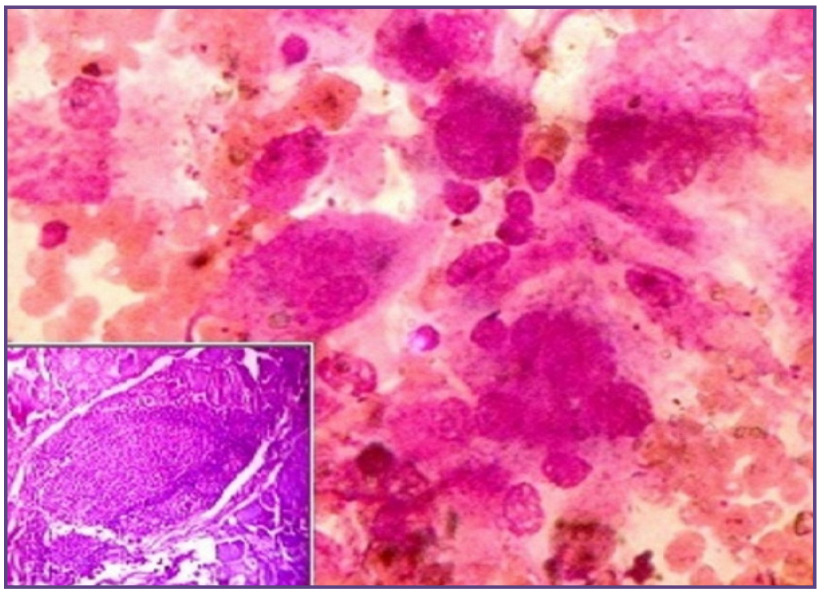

Fig. 2: FNA diagnosis- "Indeterminate" lesion in routine cytology \& Category III in BSRTC (Leishman 400X) along with on followup Histopathology image [Inset] diagnosed as Hashimoto thyroiditis (H/E 100X).

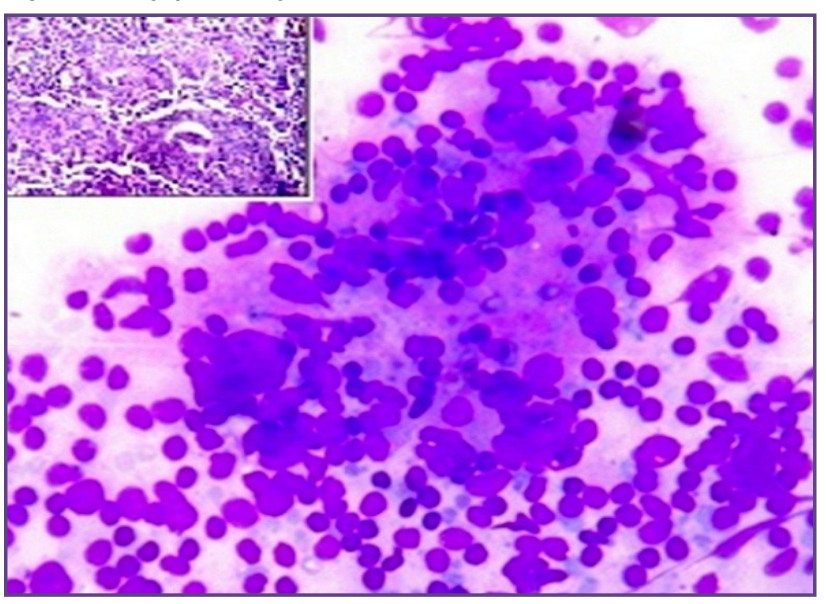

Fig. 4: FNA diagnosis- Suspicious for Lymphoma in (BSRTC Category V) [Leishman stain $400 \mathrm{X}$ ] which was confirmed on biopsy as MALT lymphoma of thyroid [H/E 400X] [Inset]

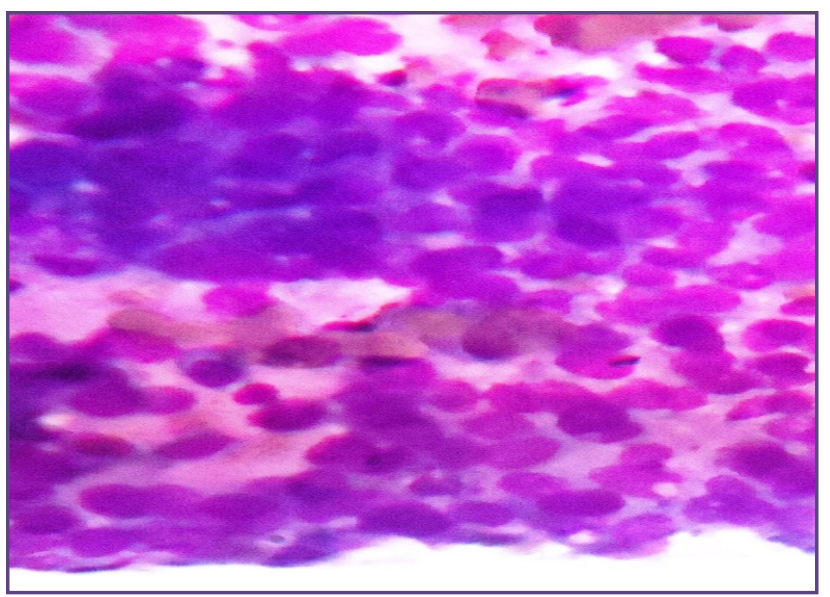

Fig. 6: FNA diagnosis- Suspicious for Poorly differentiated carcinoma in BSRTC (Category V) [Leishman stain 400X]. 


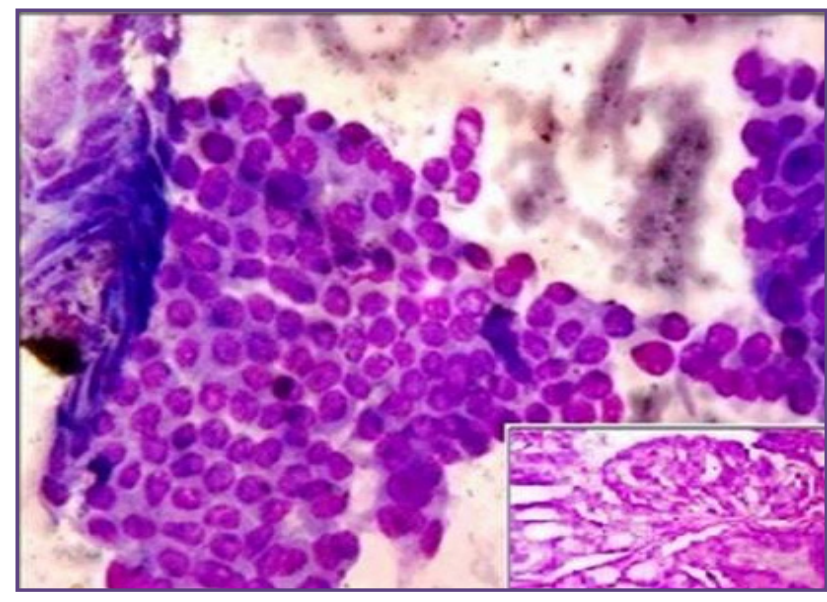

Fig. 7: FNA diagnosis- Papillary carcinoma in BSRTC (Category VI) [Leishman stain 400X] which was confirmed on biopsy [H/E 400X] [Inset].

were included into the suspicious category. They also mentioned that suspicious, and malignant categories should be counted as "Positive" and rest were counted as "Negative" for statistical assessment. In our study we also grouped "Indeterminate" and "Malignant" lesions into "Positive for neoplasia" and remaining "Unsatisfactory" along with "Benign" category were grouped into "Negative for neoplasia" for statistical assessment. In this study, some of the thyroid lesions which were diagnosed on biopsy as "Nodular Hyperplasia" and "Adenomatoid goitre" were cytologically categorized as "Indeterminate" in routine reporting system as like Nadira Mamoon et al. ${ }^{[17]}$ and caused false positivity. BSRTC is also a useful tool for the oncologist to manage those thyroid lesions. Bethesda system for thyroid reporting has six categories that increases the reproducibility of diagnosis of thyroid lesions and were logically relates to the prognosis of thyroid diseases. For example in our study, some thyroid lesions which were diagnosed on biopsy as "Nodular Hyperplasia", "Adenomatoid goitre" and "Hashimoto's thyroiditis with Hurthle cell changes", were preoperatively categorized as "Indeterminate" in routine reporting system and included under the "Positive for neoplasia" group for statistical analysis but, those lesions were categorized as "Category III" in BSRTC and grouped for "Negative for neoplasia" Henceforth, the sensitivity, specificity, PPV, NPV and Diagnostic accuracy were higher in BSRTC in relation to conventional reporting system of thyroid cytology that were also correlated with other previous studies Mamatha et al. ${ }^{[12]}$ and Bukhari et al. ${ }^{[18]}$ (Table 5). Though BSRTC were better in relation to conventional reporting system for thyroid cytodiagnosis, it also had some grey zone- mostly related to "Category III" and

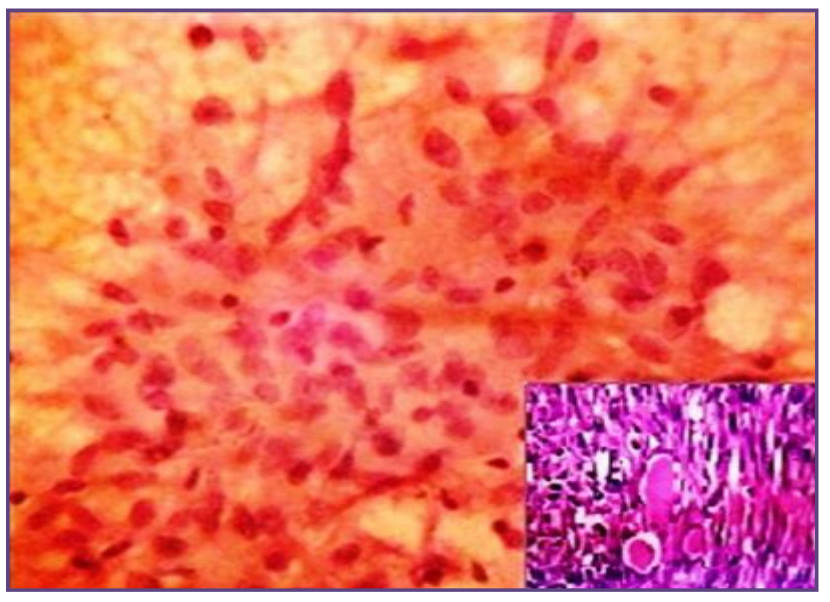

Fig. 8: FNA diagnosis- Anaplastic carcinoma in BSRTC (Category VI) $[\mathrm{H} \& \mathrm{E} 400 \mathrm{X}]$ which was confirmed on biopsy [H/E 400X] [Inset].

"Category IV" BSRTC lesions. Similar to Kasliwal et al. ${ }^{[19]}$ and Cibas et al. ${ }^{[20]}$ in our study, some false positive cases in BSRTC were also related with "Category IV" lesions e.g two cases of biopsy confirmed "Adenomatoid goitre" were categorized into "Category IV" lesions preoperatively and grouped into "Positive for neoplasia". Similarly, one case of the "Thyroglossal cyst with coexistance of Papillary carcinoma thyroid" which was diagnosed on biopsy, was preoperatively categorized under "Category III" and treated as "Negative for neoplasia" for statistical assessment which caused one false negative case.

The study might have been more statistically significant if the study period was of longer duration, study population was large and all the cases were available for follow-up and/ or biopsy, which were the major drawbacks of our study.

\section{Conclusion}

The Bethesda system of reporting thyroid cytology has lead to a better sensitivity, specificity, PPV, NPV and Diagnostic accuracy than routine cytology. BSRTC reduces Inter observer variability of thyroid lesions and hence reduces unnecessary surgical procedures for thyroid swellings. This system has standardized management protocol that may help the clinician to treat the patient well which might not be possible if reported by routine cytology system.

\section{References}

1. Naz S, Hashmi AA, Khurshid A, Faridi N, Edhi MM, Kamal A, Khan M. Diagnostic accuracy of Bethesda system for reporting thyroid cytopathology: an institutional perspective. Int Arch Med 2014;7:46-50

2. Sarda AK, Bal S, Kapoor MM. Near-total thyroidectomy for carcinoma of the thyroid. Br J Surg 1989;76:90-2. 
3. Yassa L, Cibas ES, Benson CB, Frates MC, Doubilet PM, Gawande AA et al. Long term assessment of a multi disciplinary approach to thyroid nodule diagnostic evaluation. Cancer 2007;111:508-11.

4. Cibas ES, Ali SZ. The Bethesda system for reporting thyroid cytopathology. Thyroid 2009;19:1159-65.

5. Kiernan CM, Broome JT, Solórzano CC. The Bethesda system for reporting thyroid cytopathology. A single-center experience over 5 years. Ann Surg Oncol 2014;21:3522-7.

6. Gharib H, Goellner JR, Johnson DA. Fine-needle aspiration cytology of the thyroid: a 12-year experience with 11,000 biopsies. Clin Lab Med. 1993;13:699-709.

7. Crothers BA, Henry MR, Firat P, Hamper UM. Nondiagnostic/Unsatisfactory. In, Ali SZ, Cibas ES(Eds). The Bethesda System for Reporting Thyroid Cytopathology, New York, Springer 2010:6.

8. Goellner JR, Gharib H, Grant CS, Johnson DA. Fine-needle aspiration cytology of the thyroid, 1980 to 1986. Acta Cytol 1987;31:587-90.

9. Grant CS, Hay ID, Gough IR, McCarthy PM, Goellner JR. Long-term follow-up of patients with benign thyroid fine-needle aspiration cytologic diagnoses. Surgery 1989;106:980-5.

10. Dean DS, Gharib H. Fine-Needle Aspiration Biopsy of the Thyroid Gland.. In: De Groot LJ, Chrousos G, Dungan K, et al, editors. Endotext [Internet]. South Dartmouth (MA): MD Text.com,Inc.;2000-. Available from: https://www.ncbi. nlm.nih.gov/books/NBK285544. [Accessed September 27, 2017].

11. Renshaw AA, Pinnar N. Comparison of Thyroid FineNeedle Aspiration and Core Needle Biopsy. Am J Clin Pathol 2007;128:370-4.
12. Mamatha $M$, Chandra Sekhar S, Sandhya Rani H, Sandhya Anil S, Vandana G. A comparative study between conventional system and the Bethesda system applied for reporting thyroid cytopathology. IAIM 2015;2:87-95.

13. Baloch ZW, Alexander EK, Gharib H, Raab SS. Overview of Diagnostic Terminology and Reporting. In, Ali SZ, Cibas ES(Eds). The Bethesda System for Reporting Thyroid Cytopathology, New York, Springer 2010:2.

14. Raab SS, Vrbin CM, Grzybick DM, Sudilovsky D, Balassanian R, Zarbo RJ et al. Errors in Thyroid Gland FineNeedle Aspiration. Am J Clin Pathol 2006;125:873-82.

15. Papanicolaou Society of Cytopathology Recommendations for Thyroid Fine Needle Aspiration. Available at from https://www.papsociety.org/guidelines.html. [Accessed July 27, 2017].

16. AACE/AME Task Force on Thyroid Nodules. American Association of Clinical Endocrinologists and Associazione of Medici Endocrinologi medical guidelines for clinical practice for the diagnosis and management of thyroid nodules- 2016 Update. Endocr Pract. 2006;12:63-102.

17. Mamoon N, Jamy R, Khan AH. Evaluation of fine needle aspiration cytology as a screening tool in thyroid lesions. $\mathrm{J}$ Pak Med Assoc 2013;63:1120-3.

18. Bukhari MH, Khan AA, Niazi S, Arshad M, Akhtar ZM, AlSindi KA.(2012) Better Thyroid Cytopathology Reporting System May Increase the Clinical Management and Patients Outcome. J Cytol Histol 2012;3:158-63.

19. Kasliwal N, Tanwar S, Pachori G, Gupta N, Maheshwari N, Jain D. Usefulness of Preoperative FNAC of Thyroid Swelling Along with Application of Bethesda System of Reporting. Int J Med Res Prof. 2016;2:204-9.

20. Cibas ES, Ali SZ. The Bethesda system for reporting thyroid cytopathology. Am J Clin Pathol 2009;132:658-65.

*Corresponding author:

Dr. Indranil Chakrabarti, Associate Professor, Department of Pathology, North Bengal Medical College, Sushrutanagar, District: Darjeeling. State West Bengal. Country India, Pin: 734012.

Phone: +919433187448

Email:drinch@rediffmail.com

Financial or other Competing Interests: None. 